\title{
School autonomy and educational inclusion of children with special needs: Evidence from England
}

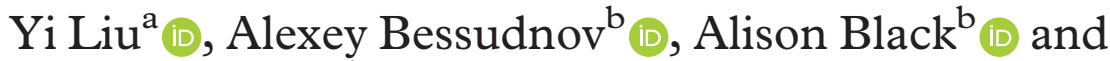 \\ Brahm Norwich $^{\mathrm{b}}$ (D) \\ ${ }^{\mathrm{a}}$ University of Bristol, $U K ;{ }^{\mathrm{b}}$ University of Exeter, UK
}

In the past few decades, several countries have introduced reforms aimed at increasing school autonomy. We evaluate the effect of the introduction of autonomous academies in England on the educational trajectories of children with special educational needs. This has been done using longitudinal data on all schoolchildren in state schools in England, from the National Pupil Database. The results show that the effects of school autonomy on educational inclusion are not uniform and depend on schools' previous performance and socio-economic composition. Schools that obtained autonomy under the control of an external sponsor (sponsored academies) were more likely to decrease the proportion of pupils with special needs and remove additional support for them. We do not observe these effects in the schools that voluntarily applied for the more autonomous status (converter academies).

Keywords: academies; school autonomy; special needs education; educational inclusion

\section{Introduction}

This article focuses on school changes in England that have involved the introduction of more autonomous state-funded schools (academies). These changes were influenced by reforms in other countries; examples include free schools (friskolor) in Sweden and charter schools in the USA. This international trend towards more school autonomy has been based on the assumption that this will release more energy and creativity in teaching and so result in greater student learning. The promise of higher school standards than those provided by the existing system is the basis of these organisational changes. Though there are differences between these countries in the type of school changes made (for instance, whether they involve new schools or existing schools that change), they all involve a move away from local or community-controlled school governance, and are based on a model of offering parents greater school choice as a way of driving up school performance standards.

\footnotetext{
${ }^{\star}$ Corresponding author. Department of Sociology, Philosophy and Anthropology, Q-Step Centre, University of Exeter, Streatham Rise, Exeter EX4 4PE, UK. E-mail: a.bessudnov@exeter.ac.uk This project has been supported by the UK Economic and Social Research Council (grant number ES/P001009/1: 'Inclusion and the academisation of English secondary schools: trends in the placements of pupils with significant SEN and those permanently excluded').
} 
There is a large international literature on the influence of school autonomy, under different conditions, on children's learning outcomes. The influence of school autonomy is best seen in terms of how schools attempt to meet their goals and values within the contemporary systems of school performance rankings, competition and accountability. The influence of these trends in school change on the provision for children with learning difficulties and disabilities, however, has been less studied. Though there have been several studies on the influence of US charter schools on pupils who require special educational services, there have been no previous studies in England. This focus on pupils with learning difficulties and disabilities connects this study to contemporary issues in inclusive education, which is commonly understood in terms of the greater academic and social participation of diverse students in a common school (Norwich \& Black, 2015). Inclusive education has become a 'global movement' (Peters, 2003), located at the forefront of international education policy agendas. Inclusive education is now framed as going beyond disability. As Slee (2008) has argued: 'typically the discussion of inclusive education is simultaneously mounted as a general examination of exclusion and inclusion for all students and a claim on behalf of a particular constituency' (p. 107). The contribution of this article is that it examines the impact of increased school autonomy in England on the education of pupils with special educational needs (SEN) within the context of the commitment to inclusive education.

\section{School autonomy, academic performance and educational inclusion}

When autonomous schools were introduced in the USA and the UK, one of the main arguments in their favour was that they would have a positive effect on academic achievement. Most of the research on school autonomy reforms and academic achievement has been done in the USA, specifically about the charter schools. Though charter schools have been operating for about 20 years, the evidence for expanding their use has been interpreted as mixed, with the longer-term outcomes, such as school graduation and college attendance, stronger than the effects on student achievement (Berends, 2015). Most studies that used lotteries in US charter schools to identify causal effects (Abdulkadiroğlu et al., 2011; Angrist et al., 2012; Dobbie \& Fryer, 2013), as well as studies of conversions of traditional public schools into charter schools (Abdulkadiroğlu et al., 2016), showed some positive effects of school autonomy on student performance (see Eyles et al., 2016 for a review of other studies and research designs). However, this is often limited to urban schools in metropolitan areas, and studies covering a wider range of areas, using similar designs, found no significant differences (Gleason et al., 2010). Berends' (2015) review concludes that the impact of charter schools on student achievement is mixed, varying from positive through neutral to negative. A meta-analysis of the evaluation studies suggests that the effect of the introduction of charter schools on academic achievement has been mostly positive (Betts \& Tang, 2016).

In the UK, there has been less research on the effects of school autonomy on pupils' achievement. Eyles and Machin (2015) studied sponsored academies set up in the 2000s to improve schools in disadvantaged areas (also see Eyles et al., 2016). They found that academy conversion resulted in the intake of pupils with higher 
attainments, fewer pupils from disadvantaged backgrounds and improvements in pupil performance. The authors point to the evidence that these performance effects tended to occur in schools with larger increases in school autonomy (e.g. head teacher and management system changes). These findings are consistent with an earlier study of sponsored academies by Wilson (2011). Wilson concluded that the pre-2010 sponsored academy programme led to a rise in school stratification. She also raised questions about whether the pursuit of academic excellence, in the government's post2010 academies and free schools programmes, would encourage these schools to adapt their admissions to a more homogenous and advantaged pupil intake. In a separate analysis, Eyles et al. (2017) studied primary schools converted to academies after 2010, and did not find that their academisation led to improved academic performance.

Overall, international evidence shows that increased school autonomy can under certain circumstances positively affect pupils' academic achievement (Eyles et al., 2016). However, there have been concerns that the reverse side of this improvement is less educational inclusion. Improved performance may be achieved at the expense of socially disadvantaged children, and children with disabilities, who may be directly or indirectly excluded from the new types of school. Barnard-Brak et al. (2018) found significantly fewer pupils with disabilities in charter schools, as compared with traditional public schools, at the national and state levels, between 2011 and 2014. Winters (2015) argued that in New York and Denver, this gap arises at the kindergarten level rather than when pupils are at school, as pupils with disabilities are less likely to apply to attend a charter school. Winters also showed that the gap is not due to more pupils with disabilities exiting charter schools than exit district ones. This is consistent with the evidence from Zimmer and Guarino (2013), who examined the exit patterns of low-achieving pupils and found no evidence to support the notion that charter schools were more likely to exclude those pupils.

Winters et al. (2017) used administrative data from Denver, CO to study the gap between charter and district schools in identifying pupils for special education in primary-aged children. Charter schools were less likely to identify specific learning disabilities, but not autism or speech or language disabilities. The gap between charter and district schools in special education seemed largely to be driven by the differences in specific learning disability category, which might be a category with less clear-cut identification criteria. Setren's (2015) study in Boston had similar findings to the Denver study. In the Boston study, pupils who were offered charter school places on a random basis were less likely to be identified for special education than pupils placed in non-charter schools, and more likely over time to be moved into less separate settings, or to be considered no longer in need of special education. Setren (2015) suggested that charter schools may prefer not to identify marginal pupils as learning disabled, offering instead intensive tutoring to help pupils catch up academically. Both Winters et al. (2017) and Setren (2015) found that pupils' enrolment in charter schools reduces the probability of being classified into special education, whereas Tuchman and Wolf (2017) found no supporting evidence of significant reclassification at intake in Louisiana's private schools.

The UK experience of academies has been more anecdotal, with some indicating that academies have shown themselves to be less willing to offer places to pupils with 
SEN, by deploying covert selection (IPPR, 2014). Galton and Mac Beath (2015), in an in-depth study of a range of English schools, reported the increased pressure on senior leaders to maintain their competitive status by not taking in pupils who might harm their academic credibility, creating what was referred to in one school as 'reputational damage' (p. 21). They also reported anecdotal evidence from some head teachers that neighbouring academies were 'cherry picking wealthier pupils' and 'excluding the neediest' (p. 49). The Academies Commission received evidence of many academies having a social inclusion commitment (Husbands et al., 2013). However, as they recognised, this did not apply to all academies, with 'some academies willing to take a "low road" approach to school improvement by manipulating admissions rather than by exercising strong leadership' (p. 7). The commission recommended that such practices be eradicated through school-to-school collaboration, as the way to improve achievement for all. Another approach has been to question critically the academisation principles for framing education as a commodity in a school marketplace (Heilbronn, 2016). Part of this argument is that the freedoms associated with academisation can come to threaten wider educational aims associated with inclusion and equity. Heilbronn argued that one of the freedoms of academies is to control student intake, as academies have some powers to determine their admission policy. She uses the Department for Education (DfE)'s exclusion data to suggest that academy schools are more likely to exclude pupils permanently, and explains this in terms of these pupils requiring more costly support than other pupils, which detracts from schools' examination performance results. Black (2019) argues that recent educational policies are actively reducing the heterogeneity of the school population. The development of different school types with different governance structures appears to lead to less diversity in the student population within each school type, heralding the arrival of a new two-tier system based on socio-economic boundaries.

In this article we contribute to this literature by analysing how the introduction of academy schools in England affected the educational trajectories of pupils with SEN. The analysis in this article is significant in illuminating current trends and the potential future of inclusive education and for exploring the consequences of the diversification of the school system in England through academisation. Before describing our research questions, data and methodology, we provide a brief review of the academisation reforms in England and educational provisions for children with SEN.

\section{School choice and diversity reform in England}

School education policy has assumed greater significance in the UK government's general social and economic policies in the past 30 to 40 years. In England the landmark legislation, the Education Reform Act 1988 (legislated by a Conservative Government), introduced an assessment-led National Curriculum, with national testing of attainments as part of a drive to raise academic standards. This was part of a wider development of a broad public service policy move from state regulation to more user choice and provision diversity (Machin \& Vignoles, 2006). This diversity of provision included more autonomy of public sector bodies, such as schools. In England, schools became more autonomous from local authority control. Parents were encouraged to exercise more choice about their children's 
school placements. This market-oriented model of schooling was continued by the Labour Government (1997-2010). In its early years, the Labour Government focused on function (raising standards, with policies such as school attainment targets) rather than on structures (school governance and whether schools were independent of local authorities). The Labour Government then responded to the issue of persistently 'failing schools' in disadvantaged areas by requiring, on a small scale, the conversion of these schools into sponsored academies, which became independent of local authority governance.

By the end of the Labour period of UK government in 2010, there was a small proportion of secondary schools which had become sponsored academies ( $6 \%$ of secondary schools in England were academies in 2010; West, 2014). The Coalition Government (2010-2015) built on this type of non-local authority school to introduce academies and free schools on a much larger scale. Higher-attaining schools were encouraged to convert to academies and be self-governing (this is the converter type of academy) while other schools were required, because of poor performance, to become academies under the control of external sponsors (this is the sponsored type of academy, the type set up by the Labour Government). The external sponsor was charged with driving up school performance standards. Free schools were new schools set up under the initiative of parents, voluntary organisations or religious groups; some of these might be special schools for specific groups of pupils with SEN and disabilities. Free schools operate like academies in having more autonomy than maintained schools in terms of their organisation, curriculum and staffing, though they are not permitted to formally select pupils by attainment and ability. All pupils with a Statement of SEN or an Education, Health and Care (EHC) Plan have to be admitted to an academy if the school is named in the Statement or Plan.

Eyles et al. (2018) compared the characteristics of the sponsored and converter academies and found that the two batches of academies were very different. Schools that became sponsored academies (both before and after 2010) had lower levels of academic attainment and a higher share of disadvantaged pupils. By contrast, converter academies were usually better schools with higher academic results. After conversion, sponsored academies were more likely than converter academies to improve the student intake in terms of previous academic attainment in primary school. It is unclear whether the mechanism for this improvement was parental choice or new school policies (or both), but Eyles et al. (2018) conclude that concerns about higher school socio-economic segregation as a consequence of the academisation reform are 'partly warranted'. Note that this mostly applies to sponsored rather than converter academies. We will use this distinction in our analysis.

A survey of 720 academies, conducted by Cirin (2014), showed that academies did use their autonomy. The most common changes were: externally procuring services previously supplied by the local authorities (90\% of academies); linking pay to performance $(84 \%)$; and changing, or planning to change, the curriculum (79\%). Academies that had been open for a longer period made more changes. Both sponsored and converter academies reported a substantial increase in first-choice applications since becoming an academy, and the increase was greater in sponsored academies. 


\section{Academies and provisions for children with special educational needs}

It is important to clarify the use of terms in referring to pupils with SEN. According to the 2014 Children and Families Act, special educational needs is the legal term that refers to pupils in England who have difficulties in learning and require additional or different provision. This may involve provision either in an ordinary school that makes adaptations for children with SEN, or in a special school.

SEN covers a wide range of difficulties in the areas of cognitive, language, motor, sensory, emotional, behavioural and communication functioning. Since its introduction in 1981, the term 'SEN' has been qualified as a characteristic that differs by degree. From 2001 to 2014, there were three levels of SEN: School Action; School Action Plus (both of which were identified by school staff); and Statement (which involved a legally based record of provision identified by a multi-professional team that took into account parental views). By 2014, about $20 \%$ of pupils were identified as having SEN at one of these three levels. With the 2014 legislation, and subsequent new SEN Code of Practice, these three levels were reduced to two. Schools now identify the larger number of pupils as having SEN at what is called the SEN Support level for those with less severe difficulties, while local authorities identify the smaller number of pupils with more severe difficulties at what is called the Education, Health and Care Plan (EHCP) level, replacing the Statements.

The choice and diversity initiatives in English education have extended to SEN policy and practice. Parental choice and provision diversity were retained, alongside a commitment to social inclusion, by New Labour when in government. The term 'inclusive education' came to be written into government policy and the presumption was that the policy direction was indeed towards more inclusive education (Norwich, 2014). This was consistent with the international policy trends towards greater inclusive education as expressed by the Salamanca Declaration. Labour introduced disability discrimination legislation into the education sector through its 2001 Special Educational Needs and Disability Act, meaning that schools now had a duty as regards pupils with disabilities, alongside their responsibilities under the SEN Code of Practice. From 2010, the Coalition Government reviewed SEN and inclusion policy and introduced changes based on a move away from what was initially described as the previous 'bias to inclusion' (DfE, 2011). The Coalition Government proposed policy to 'strengthen parental choice by improving the range and diversity of schools from which parents can choose, making sure they are aware of the options available to them' (p. 5). This was achieved by legislative changes that established greater parental choice in placement for children with SEN.

The introduction of academies in English education, and the changes in SEN identification rules and practices, occurred during approximately the same period. Figure 1 illustrates both trends with the data from the National Pupil Database (described below in the Data section). The left-hand panels show the rising number of converter and sponsored academies among English secondary schools. By 2015 (the last year of our analysis), 33\% of all secondary schools were converter academies and another $12 \%$ were sponsored academies. The trend continued after 2015, and now the majority of English secondary schools have become academies. 

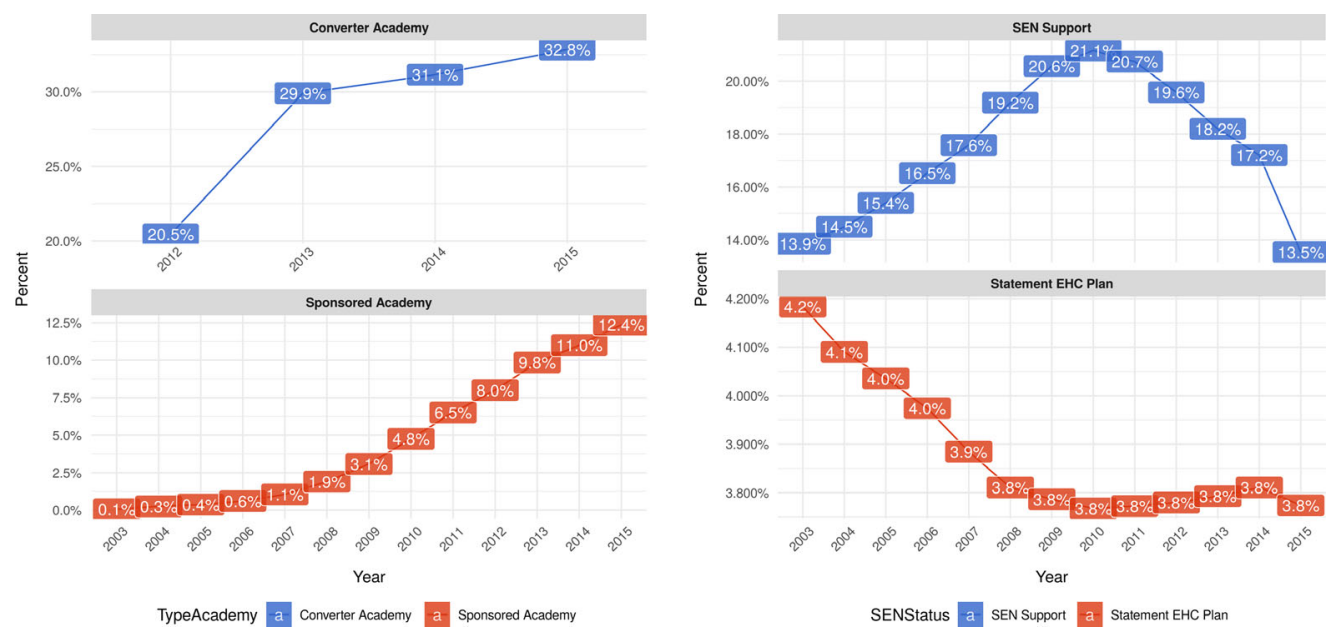

Figure 1. Trends of academisation of English secondary schools and SEN inclusion.

Note: This figure reports (1) the percentage of secondary academies over all secondary schools in England and (2) the percentage of secondary pupils with a special educational needs status over all secondary pupils. Data: National Pupil Database [Colour figure can be viewed at wileyonlinelibrary.com]

The right-hand panels in Figure 1 show the changing trends in the proportion of all pupils with SEN Support (less severe SEN) and with EHC Plans (more severe SEN). For EHCP, there was some small decline in the proportion of children identified from 2003 to 2008, but after this it remained stable. For SEN Support, however, the changes are more visible. First, we see the increase in the proportion of pupils with SEN Support (that at the time included School Action and School Action Plus categories), from 14\% to 21\% between 2003 and 2010. Then, after the Coalition Government assumed office in 2010 and introduced changes in education policy that included both converting more schools to academies and new SEN guidelines, we see the decrease in the proportion of children with SEN Support back to about $13 \%$ by 2015 . Obviously, correlation does not mean causation, but one may wonder to what extent these two trends (the academisation of schools and the decreasing proportion of children with SEN Support) are related.

\section{Research questions}

The main objective of this article is to explore the effects of converting English schools to academies, on the educational trajectories of children with SEN. The descriptive evidence presented above suggests that academies may be less likely to enrol children with SEN. Thus, our first research question explores changes in the proportion of SEN children at the school level.

RQ1: Does converting schools to academies lead to a change in the proportion of children with SEN at the school level? 
If the proportion of SEN children changes after a secondary school becomes an academy, this can be the result of several processes. First, parents of children with SEN may change their preferences for school placement of their children. Second, schools may discriminate against children with SEN at the point of admission in Year 7. Third, schools may reclassify children with SEN at the point of admission in Year 7 or in later years. Finally, children with SEN may be more likely to leave the school after it becomes an academy.

Without full data on school applications made by parents, it is not possible to answer the question on whether parental preferences change following conversion to academies. Exploring discrimination at the point of admission ideally requires experimental data. When it comes to exploring mechanisms behind the change in proportions of pupils with SEN, in this article we are primarily concerned with the effect of academy conversions on reclassification of children with SEN, and on them leaving school.

Our second research question asks about the effect of academy conversions on changing the SEN status of children at the point of admission to secondary school in Year 7.

RQ2: Do schools that convert to academies become more likely to change the SEN status of children at the point of admission in Year 7 ?

Note that, as described above, schools are only able to change the SEN status of children with milder forms of special educational needs (SEN Support). Changing provisions for children with more severe forms of SEN (EHC Plan) requires approval at the local authority level. We look at the effects on both types of SEN separately. We explore reclassification in both directions (i.e. the removal of SEN status from children who had it in the last year of primary school, and the assignment of SEN status to children who did not have it in the last year of primary school).

Our third research question explores SEN reclassification effects for children who were already enrolled in a school at the time of academy conversion.

RQ3: Do schools become more likely to change the SEN status of enrolled pupils after converting to academies?

Our final question deals with the effect of academy conversions on children with SEN leaving school.

RQ4: Are pupils with SEN in schools that become academies more likely to leave school after academy conversion?

Since the characteristics of sponsored and converter academies are very different (Gorard, 2014; Eyles et al., 2018), we answer each research question separately for each type of academy conversion.

\section{Data and variables}

Our data come from England's National Pupil Database (NPD), covering academic years $2002 / 2003$ to $2014 / 2015$. The NPD contains administrative pupil-level data 
about all children of school age in England. For this study, we mainly use Pupil Level Annual School Census (PLASC) data, collected from schools in the state sector by the DfE. These data are provided in the form of cross-sectional files, each containing over 7 million records on individual children enrolled in English schools (excluding privately funded schools). Each child has an anonymised ID number that is constant over time and allows us to construct longitudinal pupil-level files for each school cohort.

The variable of primary interest for us is SEN status. Following the official DfE classification introduced in 2014 (DfE, 2014), it is coded at three levels: 'No SEN' (NoSEN); 'SEN Support' (SENS); and 'Statement EHC Plan' (EHC), as discussed above. Prior to 2014, the official classification of SEN was different, and to harmonise it we recoded 'School Action' and 'School Action Plus' into 'SEN Support', and 'Statement' into 'Statement EHC Plan'. We also use data on a pupil's gender, ethnicity, free school meal status (a proxy for the family's socio-economic status) and on whether English is their first or an additional language.

Schools in the NPD are identified by a unique reference number (URN). When a school changes its type (for example, when a school becomes an academy), it is likely to gain a new URN. When changing type, several schools can merge into one. We use the official Open Academies data set (DfE, 2018) to track the continuous history of academies and link them to predecessor schools. We include schools that became academies from September 2002 to February 2018 in the cases of 'one-to-one' and 'many-to-one' school conversions, and exclude the rare cases of 'many-to-many' conversion. Table 1 reports the number of schools in our study sample.

To analyse school-level effects, we construct a longitudinal school-level sample of aggregate measures. In the case of multiple predecessors, we replace them with one hypothetical predecessor with average values, weighting by the total number of pupils in predecessor schools. Table 2 reports descriptive statistics for our sample.

\section{The identification strategy and statistical modelling}

A naive approach to identifying the effects of converting schools to academies would be to compare the outcomes of academies and schools that remained maintained by local authorities. An obvious problem with this approach is that the academies and

Table 1. Academy conversions

\begin{tabular}{lccccc}
\hline & \multicolumn{2}{c}{ Converter academies } & & \multicolumn{2}{c}{ Sponsored academies } \\
& One to one & Many to one & & One to one & Many to one \\
\hline $2003-2006$ & 0 & 0 & & 12 & 3 \\
$2007-2010$ & 0 & 0 & & 106 & 21 \\
$2011-2013$ & 1,188 & 3 & & 161 & 30 \\
$2014-2017$ & 236 & 19 & & 195 & 13 \\
Sep 2017-Feb 2018 & 32 & 3 & 24 & 30 \\
\hline
\end{tabular}

Note: This table reports the number of English secondary schools that became academies for each range of academic years. 
Table 2. School characteristics

\begin{tabular}{lccccccccc}
\hline $\begin{array}{l}\text { Type of } \\
\text { school }\end{array}$ & Year & $\begin{array}{c}\text { No. } \\
\text { schools }\end{array}$ & $\begin{array}{c}\text { No. } \\
\text { pupils }\end{array}$ & $\begin{array}{c}\% \\
\text { Male }\end{array}$ & $\begin{array}{c}\text { \% FSM } \\
\text { eligible }\end{array}$ & $\begin{array}{c}\text { \% White } \\
\text { British }\end{array}$ & $\begin{array}{c}\text { \% English } \\
\text { as first } \\
\text { language }\end{array}$ & $\begin{array}{c}\text { \% SEN } \\
\text { Support }\end{array}$ & \% EHCP \\
\hline Maintained & 2003 & 4,606 & $2,980,823$ & 51 & 16 & 80 & 91 & 14 & 4.11 \\
school & 2010 & 3,955 & $2,697,908$ & 51 & 15 & 77 & 88 & 21 & 3.78 \\
& 2015 & 1,951 & $1,072,452$ & 51 & 17 & 70 & 83 & 13 & 5.60 \\
Sponsored & 2003 & 3 & 2,650 & 51 & 45 & 62 & 78 & 29 & 2.34 \\
academy & 2010 & 201 & 162,452 & 52 & 28 & 67 & 82 & 29 & 2.33 \\
Converter & 2015 & 556 & 403,368 & 52 & 25 & 68 & 81 & 17 & 2.30 \\
academy & 2012 & 841 & 771,910 & 50 & 10 & 78 & 90 & 17 & 2.07 \\
\hline
\end{tabular}

Note: This table reports the descriptive statistics for secondary schools in our sample.

maintained schools have different baseline characteristics, and if we find any outcome differences between these two groups of schools, it will be unclear whether they are the effect of the academisation or of the underlying baseline differences. Statistically controlling for the baseline characteristics can only partially mitigate this problem.

Instead, our identification strategy relies on the comparison between the schools that had become academies (the 'treatment' group) and the schools that were yet to become academies (the 'control' group) at the time of comparison. The identifying assumption is that the exact timing of academy conversion is exogenous (independent of school's baseline characteristics) and there are no systematic differences between the schools that followed the academisation route at different points of time. This is the identification strategy previously used in several works by Eyles and coworkers that explored the effects of academisation on academic performance (Eyles \& Machin, 2015; Eyles et al., 2016, 2017), and it has been shown that this identifying assumption generally holds (Eyles et al., 2018). Essentially, we employ a differencein-differences approach, comparing the difference in the outcome measures before and after academisation for the schools that had become academies with the difference in the outcome measures in the same period for the schools that were yet to become academies.

Therefore, our sample consists only of schools that at some point became converter or sponsored academies, which excludes schools that remained maintained by local authorities as of 2018. The effect of the academisation, on a school or a pupil, can be derived from a linear fixed-effects model as an average treatment effect (ATE).

In general, for each of the outcomes of interest, a linear fixed-effects model is specified as:

(1) $y_{i s t}=\delta A_{i s t}+\boldsymbol{X}_{i s t}^{\prime} \beta+\alpha_{s}+\alpha_{t}+\epsilon_{i s t}$,

where $A_{\text {ist }}$ denotes the binary academisation status, with $A_{i s t}=1$ when school $s$ with pupil $i$ enrolled in year $t$ is an academy; $y_{i s t}$ denotes the outcomes related to SEN status; and $\boldsymbol{X}_{i s t}$ is a vector of control variables. $\delta$ is the average difference in the pupillevel measures between the pupils whose schools converted to academies at time $t$ and the pupils whose schools are yet to convert to academies at time $t$. We also control 
for school and time fixed effects. At the pupil level, we use linear probability models for all binary outcomes, and the coefficient for the academisation variable can be interpreted directly as the average change in outcome probability as a result of academisation.

Specifically, we are interested in the academisation effects on SEN status at the following two stages: at the Year 7 admission stage ('intake') and during secondary education from Year 7 to Year 11 ('within').

\section{'Intake' models}

For SEN pupils finishing their primary schooling, there are several possible scenarios regarding their enrolment in a secondary school. They can enrol in a new school and keep their existing SEN status, or be reclassified with a different SEN status (e.g. from SEN Support to No SEN, or from SEN Support to EHC Plan, etc.). Similarly, pupils without SEN status in Year 6 of primary school can keep their status when they enrol in a secondary school in Year 7 or be reclassified as SEN Support or EHC Plan.

If academy conversion has an effect on SEN status, we would expect that more SEN pupils lose their SEN status at admission following the conversion, and fewer non-SEN pupils gain SEN status.

We investigate the academisation effects on the following outcome measures.

1. At the school level, the percentage of Year 7 pupils classified with a specific SEN status: $P_{s t}=\frac{N_{s t}(\text { SEN pupils })}{N_{s t}(\text { all pupils })} \times 100 .($ RQ1)

2. At the school level, the percentage of Year 7 pupils that have been reclassified over all Year 7 pupils in a school: $P_{s t}^{\prime}=\frac{\sum_{N_{s t}(\text { all pupils })} R_{i t}}{100 .(\mathrm{RQ} 2)}$

3. At the pupil level, the probability of reclassifying pupils' SEN status from their Year 6 status to another status at Year 7: $R_{i s t}=I\left(l_{t-1} \rightarrow l_{t}^{\prime}\right), l \neq l^{\prime}$ $\in\{$ SENS, NoSEN, EHC $\}$. (RQ2)

In the pupil-level models, the following control variables are included: gender; free school meal (FSM) status; being White British; having English as first language. For the school-level models, control variables include the number of Year 7 pupils and the aggregated pupil-level control variables (gender, FSM, etc.) as a percentage of total number of Year 7 pupils in the school.

\section{'Within' models}

When a school becomes an academy, the pupils in Years 7 to 11 may become more likely to lose their SEN status or less likely to gain it. The SEN pupils may also become more likely to leave the school. Since our data are longitudinal, in many cases we can observe these outcomes several years after the academisation of the school.

For the 'within' models we investigate the following outcome measures.

1. The probability of reclassification of the SEN status after the academisation of the school: $R_{i s t}^{\tau}=I\left(l_{t-1} \rightarrow l_{t+\tau}^{\prime}\right), l \neq l^{\prime} \in\{$ SENS, NoSEN $\}$. (RQ3)

2. The probability of exiting school: $S_{i s t}^{\tau}=I\left(s_{t-1} \neq S_{t+\tau}\right)$. (RQ4) 
Pupils and their parents may know in advance about their school's intention to become an academy. This potentially introduces a bias in our analysis, since parents who are not happy with the school's decision may leave the school before the academy conversion takes place. On the contrary, some parents might only send their children to a school if it becomes an academy. To solve this problem, we use school enrolment in the year preceding conversion to an academy (legacy enrolment) as an instrumental variable to obtain a local ATE (Imbens \& Angrist, 1994). This is the effect of the academisation on 'compliers' (i.e. pupils who would have stayed in the school whether the school became an academy or not). Legacy enrolment in the school prior to the treatment event was used in several studies, including Abdulkadiroğlu et al. (2016) on charter schools in the USA, Fryer (2014) on public schools in the USA, Eyles and Machin (2015) and Eyles et al. (2017) on academisation in England. Note that an instrumental variable specification is not applicable to the intake models; legacy enrolment is not defined for Year 7 pupils, since this is their first year in secondary school. The details of this estimation strategy are available in Appendix A.

\section{Results}

In Table 3 we report the effects of academisation on the school- and pupil-level outcomes from the intake models. Note that in the tables we only report the coefficients for the academisation variable $(\delta)$; we control for all other variables as described above, but do not report the coefficients. At the school level, we look at the effects of changing a school into a converter or sponsored academy on the proportions of pupils in the various categories of SEN. At the pupil level, we look at the effects on the proportions of pupils who experienced any of the various possible SEN status changes.

We find that for converter academies the effects are small, even when statistically significant (since we analyse the population data, even very small effects are statistically significant). We see that as a result of converter academisation the percentage of pupils who do not have SEN status in Year 7 increases by 0.5 percentage points (pp), and the percentage of pupils reclassified from SEN Support to No SEN increased by $0.2 \mathrm{pp}$.

For sponsored academies the effects are much stronger. As a result of sponsored academisation, the percentage of pupils without SEN status (No SEN) increased by $1.9 \mathrm{pp}$, and the percentage of pupils reclassified from SEN Support to No SEN in Year 7 increased by 1.1 pp. As of 2015 (see Table 2), 17\% of pupils in sponsored academies had SEN Support, and about a 2 pp change is a noticeable decrease.

The analysis at the pupil level confirms these findings. The effects of converter academisation on SEN reclassification outcomes are very close to zero. For sponsored academies, however, academisation resulted in an increase in probability of a pupil with SEN Support in Year 6 being reclassified to No SEN of $4.0 \mathrm{pp}$. At the same time, the probability of a pupil without SEN Support in Year 6 gaining that status in Year 7 decreased by $1.6 \mathrm{pp}$.

These numbers need to be put in context by looking at the total proportions of pupils whose SEN status changed at admission to secondary school. As shown in Figure 2, the proportion without SEN in Year 6 who got SEN Support in Year 7 decreased between 2006 and 2014 for all types of schools; but the decrease in 
Table 3. 'Intake' models: regression results

\begin{tabular}{lll}
\hline & \multicolumn{2}{c}{ Coefficient $(\mathrm{SE})$} \\
\cline { 2 - 3 } & Converter academies & Sponsored academies \\
\hline School-level measures & & \\
$\%$ NoSEN & $0.456^{* *}(0.225)$ & $1.851^{* * *}(0.532)$ \\
$\%$ SENS & $0.333(0.232)$ & $-1.658^{* *}(0.541)$ \\
$\%$ EHC & $-0.124^{*}(0.075)$ & $-0.193(0.157)$ \\
$\%$ NoSEN $\rightarrow$ SENS & $-0.035(0.132)$ & $1.135^{* *}(0.283)$ \\
$\%$ SENS $\rightarrow$ NoSEN & $0.224^{*}(0.117)$ & 12,123 \\
No. observations & 29,359 & $-0.016^{* *}(0.007)$ \\
Pupil-level measures & & $0.0001(0.0001)$ \\
NoSEN $\rightarrow$ SENS & $-0.002(0.010)$ & $0.040^{* * *}(0.014)$ \\
NoSEN $\rightarrow$ EHC & $0.0001^{*}(0.0001)$ & $-0.001(0.002)$ \\
SENS $\rightarrow$ NoSEN & $-0.001(0.010)$ & $0.0003(0.006)$ \\
SENS $\rightarrow$ EHC & $-0.001(0.002)$ & $0.011^{*}(0.006)$ \\
EHC $\rightarrow$ NoSEN & $-0.001(0.002)$ & 613,089 \\
EHC $\rightarrow$ SENS & $-0.004^{* *}(0.002)$ & \\
No. observations & $1,534,469$ & \\
\hline
\end{tabular}

Note: This table reports coefficient and standard error estimates of $\delta$ for intake models. For pupil-level reclassification models, coefficients measure the change in the probability $([0,1]$ scale) of reclassifying from one SEN status to another SEN status for a pupil. For school-level measures, coefficients measure the change in the percentage points. We report heteroscedasticity-robust standard errors clustered at the school level. All the models control for pupils' gender, free school meal status, being White British and having English as an additional language. For school-level models, these controls are aggregated measures.

${ }^{*} p<0.1$.

$* * p<0.05$.

$* * * p<0.01$.

sponsored academies was particularly steep. In 2006, $13 \%$ of No SEN pupils admitted to sponsored academies gained SEN Support status, while in 2014 this number decreased to 5\%. The number of pupils with SEN Support in Year 6 who lost it in Year 7 remained stable at the relatively high level of about $25 \%$, both in academies and maintained schools, and further increased to $35-40 \%$ in 2014 .

We do not find noticeable effects of school academisation on the transition to and from EHCP status. This is not surprising given that the EHCP is determined by local authorities and is mostly outside school control. We exclude EHCP from further analyses and focus on SEN Support only.

In Table 4 and Figure 3, we report the effects of academisation on the reclassification outcomes for 'within' models (i.e. from Year 7 to 11), both in the standard fixedeffects and instrumental variable specifications. We find that our model specifications are robust to endogeneity from pupils changing schools strategically, as the estimated coefficients for both specifications are similar in direction and magnitude. The results are reported separately for period 0 (the year of academisation) and periods up to 2 years after that.

As with the intake models, we find strong differences in the effects for converter and sponsored academies. For converter academies, there is no effect of academisation on the reclassification from No SEN to SEN Support; in other 


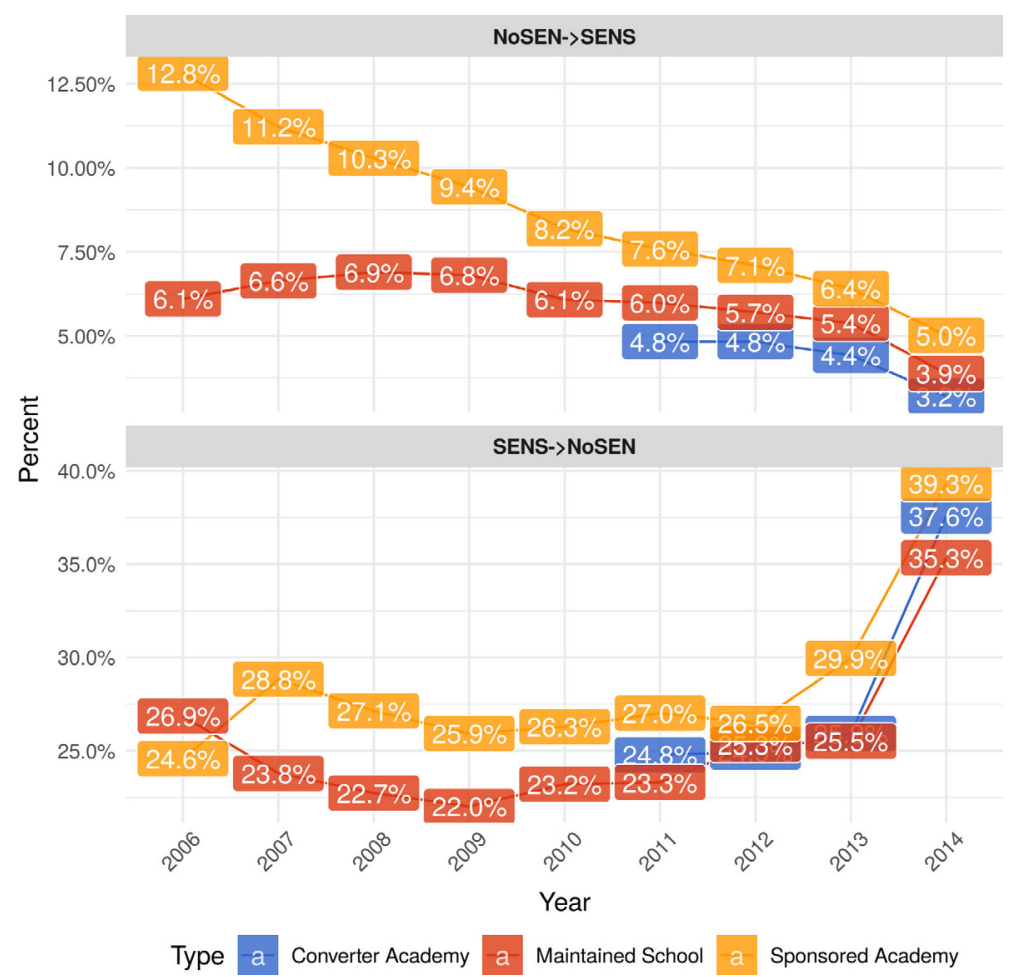

Figure 2. The trend of reclassification at intake for English secondary schools.

Note: This figure reports the percentage of pupils reclassified from their Year 6 SEN status to another SEN status at Year 7 by the type of school [Colour figure can be viewed at wileyonlinelibrary.com]

words, pupils do not become more or less likely to get SEN Support following academisation. Moreover, starting from a year after academisation, SEN Support pupils in converter academies become somewhat less likely (by approximately $2 \mathrm{pp)}$ to lose SEN Support.

The effects of sponsored academisation are in the opposite direction. When a school becomes a sponsored academy, pupils without SEN Support become $0.7 \mathrm{pp}$ less likely to gain it, and the effect persists in the following academic year. At the same time, pupils with SEN Support become about $2 \mathrm{pp}$ more likely to lose it (3 pp in the instrumental variable specification), again with the effect both in the year of academisation and the following year.

Finally, we estimate the effects of academisation on the probability of leaving school (Table 5). We find that academisation, both converter and sponsored, in fact leads to a higher probability of pupils staying in school, regardless of pupils' SEN status. For example, pupils identified with SEN Support at the baseline period are $0.5 \mathrm{pp}$ and $0.7 \mathrm{pp}$ less likely to leave converter academies and sponsored academies, respectively, 2 years after academisation. Similarly, pupils without SEN Support at the baseline period are $0.5 \mathrm{pp}$ less likely to leave converter academies and $1.3 \mathrm{pp}$ less likely to leave sponsored academies 2 years after academisation. 
Table 4. 'Within' models: regression results for reclassification measures

\begin{tabular}{|c|c|c|c|c|}
\hline \multirow[b]{2}{*}{ Period } & \multicolumn{2}{|c|}{ Converter academies } & \multicolumn{2}{|c|}{ Sponsored academies } \\
\hline & Baseline & IV & Baseline & IV \\
\hline \multicolumn{5}{|l|}{ NoSEN $\rightarrow$ SENS } \\
\hline 0 & $-0.0003(0.001)$ & $0.002(0.001)$ & $-0.007 * *(0.003)$ & $-0.007 * *(0.003)$ \\
\hline 1 & $-0.001(0.001)$ & $0.003 *(0.002)$ & $-0.008 * *(0.004)$ & $-0.007 *(0.004)$ \\
\hline 2 & $0.0003(0.002)$ & $0.001(0.002)$ & $-0.004(0.004)$ & $-0.003(0.005)$ \\
\hline No. observations & $8,169,226$ & & $2,918,295$ & \\
\hline \multicolumn{5}{|l|}{ SENS $\rightarrow$ NoSEN } \\
\hline 0 & $-0.005(0.007)$ & $0.003(0.007)$ & $0.022 * *(0.010)$ & $0.032 * * *(0.010)$ \\
\hline 1 & $-0.019 * *(0.008)$ & $-0.012(0.009)$ & $0.024 * *(0.012)$ & $0.033 * * *(0.010)$ \\
\hline 2 & $-0.022 * *(0.009)$ & $-0.019 * *(0.010)$ & $0.003(0.012)$ & $0.010(0.013)$ \\
\hline No. observations & $1,579,408$ & & 935,646 & \\
\hline
\end{tabular}

Note: This table reports the coefficient and standard error estimates of $\delta$ (ATE coefficient) and $\delta^{\prime}$ (LATE coefficient) for within reclassification measures. Coefficients measure the change in the probability $([0,1]$ scale) of a pupil being reclassified to another SEN status. We report heteroscedasticity-robust standard errors clustered at the school level. All the models control for pupils' gender, free school meal status, being White British and having English as an additional language.

$* p<0.1$.

$* * p<0.05$.

$* * * p<0.01$.

\section{Discussion and conclusion}

This article focuses on a novel aspect of the introduction of more autonomous statefunded schools in England, which is the impact of the introduction of academy schools on the intake, labelling and exit of pupils with SEN. What is distinctive about this study is the specific English form of school autonomy and the national scale of the data set used to examine the research questions. As discussed above, some sources report covert selection and 'cherry picking' by academies, while others report at least some academies with a social inclusion commitment. The main conclusion from our analysis is that the effect of school autonomy on educational provision for pupils with SEN is not uniform, but depends on the type of school.

In our first research question, we asked whether converting a secondary school to an academy affects the proportion of pupils with SEN newly admitted in Year 7, the first year of secondary school. We found that the answer depends on the type of academy. Converter academies were mostly high-achieving schools, encouraged to become academies when ranked by the inspectorate as outstanding, or good with outstanding features. They voluntarily applied to become academies and obtain more autonomy from local authorities. By contrast, sponsored academies were poorly performing schools that were required to convert to academies by the government and obtained greater autonomy under the control of an external sponsor (New Schools Network, 2015). According to our data, academisation has not had much effect on the SEN status of new student cohorts in converter academies. However, for sponsored academies the effect was much stronger and obtaining greater autonomy resulted in a decrease in the proportion of pupils with SEN Support. 


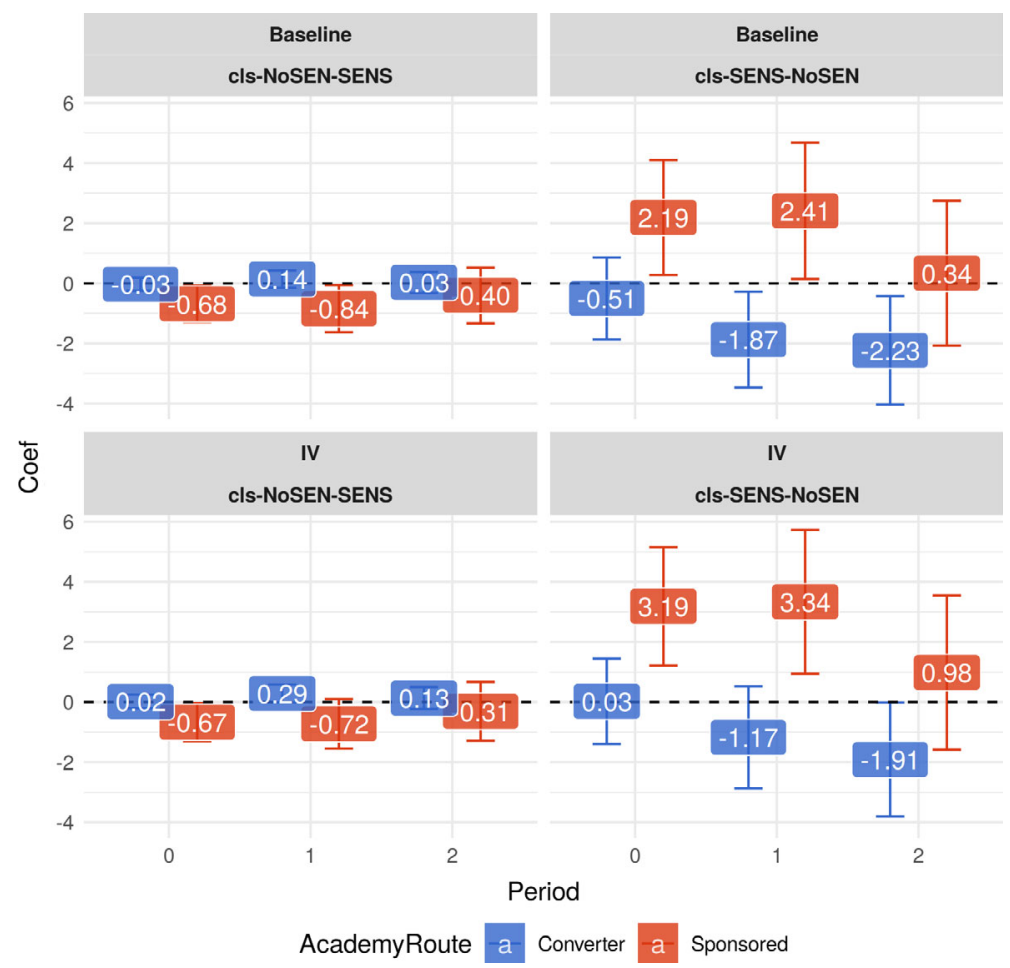

Figure 3. Academisation effects on reclassification of SEN status, 'within' models for Year 7 to Year 11 pupils. Note: Coefficient estimates have been scaled to percentage points to simplify interpretation [Colour figure can be viewed at wileyonlinelibrary.com]

In our second and third research questions we asked if academisation resulted in a greater probability of new and already enrolled pupils changing their SEN status. The answer again depends on the school type. Both school-level and pupil-level analyses show that sponsored academies, but not converter academies, were more likely after obtaining more autonomy to take away SEN Support from their pupils.

Our final research question was about the school exit pattern, after academisation, of pupils with SEN. We found that irrespective of their SEN status, pupils were less likely to leave both converter and sponsored academies.

All these findings are for the less significant, higher incidence type of SEN (SEN Support) rather than for the more significant, lower incidence type of SEN (EHC Plan). The EHC Plans are under the control of local authorities, and involve a systematic statutory system of assessment and needs, not required for SEN Support. Were any changes at the school level likely to affect the proportions of pupils with EHC Plans, this would be indirect and mediated by other factors and so likely to have minor effects. Indeed, we did not find any important effects of academisation on pupils with EHC Plans.

How can we explain these results and the difference between the two types of academy? Sponsored academies, following academisation, may have reduced the proportion of pupils with SEN, and become more likely to change pupils' SEN status, for several reasons. Previous studies found that pre-2010 sponsored academisation 
Table 5. 'Within' models: regression results for leaving school

\begin{tabular}{lll}
\hline & \multicolumn{2}{c}{ Coefficient (SE) } \\
\cline { 2 - 3 } & Converter academies & Sponsored academies \\
\hline SENS & & \\
0 & $-0.001^{* *}(0.001)$ & $-0.001(0.001)$ \\
1 & $-0.002^{*}(0.001)$ & $-0.005^{* *}(0.002)$ \\
2 & $-0.005^{* *}(0.003)$ & $-0.007^{*}(0.004)$ \\
No. observations & $1,579,408$ & 935,646 \\
NoSEN & $0.000(0.000)$ & $-0.000(0.001)$ \\
0 & $-0.001(0.001)$ & $-0.006^{* * *}(0.002)$ \\
1 & $-0.005^{* * *}(0.002)$ & $-0.013^{* * *}(0.003)$ \\
2 & $8,169,226$ & $2,918,295$ \\
\hline No. observations & & \\
\hline
\end{tabular}

Note: This table reports coefficient and standard error estimates of $\delta$ for leaving school as a result of academisation. The coefficients measure the change in the probability $([0,1]$ scale) of a pupil leaving school following academisation. We report heteroscedasticity-robust standard errors clustered at the school level. All the models control for pupils' gender, free school meal status, being White British and having English as an additional language.

${ }^{*} p<0.1$.

$* * p<0.05$.

$* * * p<0.01$

resulted in the intake of pupils with higher attainments and fewer pupils from disadvantaged backgrounds (Wilson, 2011; Eyles \& Machin, 2015; Eyles et al., 2016). Having special educational needs, especially at the less significant level, is correlated with socio-economic disadvantage. Reducing the intake of pupils from disadvantaged backgrounds is also likely to reduce the intake of those with SEN.

Sponsored academies change their status to have a fresh start, with the goal of raising academic standards in challenging social circumstances. They have higher proportions of pupils with SEN than converter academies (Norwich \& Black, 2015). They may focus on raising standards for all low-attaining pupils and so comply with the inspection agency's advice to reduce the over-identification of SEN. Reducing the proportions of pupils with SEN in the school may also be seen to have reputational benefits, without losing SEN funding that can be redirected to those with more significant SEN. Converter academies have lower baseline proportions of pupils with SEN, and their focus following academisation is less likely to be about SEN provision than in sponsored academies.

We have established one of the mechanisms that drove the decrease in the proportion of pupils with SEN in sponsored academies. Sponsored academies were more likely to change the SEN status of pupils they admitted, as well as that of pupils who were enrolled at the time of academisation. Other potential mechanisms are: the effect of academisation on parental school preferences (parents of children with SEN may become less likely to apply to a school after it becomes an academy); direct or indirect discrimination against pupils with SEN at admission; or a combined effect of the change in parental preferences and school policies. So, with the data we have, we are unable to answer the question of whether sponsored academies discriminate 
against applicants with SEN. To answer this question would require the application of experimental methods. However, it is clear that something is acting as a barrier to the inclusion of children with SEN in sponsored academies.

We can also put these findings in an international context. We should be careful with direct cross-national comparisons, but despite the differences between academies in England and US charter schools, the results of our study can be related to some US studies. Barnard-Brak et al. (2018) found significantly fewer pupils with disabilities in charter schools, at the national and state level. Winters et al. (2017) showed that charter schools, compared to district schools, reduced the classification of disability in Denver primary-aged children; but mostly for learning disability (a high-incidence, and sometimes contested, category) and not autism or speech or language disability (often seen to have more objective classification criteria). This might be related to our findings about the differences between SEN Support and EHC Plans in England.

This study also found that academisation, for both converter and sponsored types, leads to a higher probability of pupils staying in the same school, regardless of pupils' SEN status. This has similarities to US studies of charter schools that did not find evidence to support the notion of push-out by these charter schools (Zimmer \& Guarino, 2013).

Inclusion is a complex concept that cannot be captured within a single sentence. The concept of inclusion is multidimensional and relates to presence in local schools, academic participation, social participation or belonging and achievement in a common curriculum framework. A common criterion in most definitions is achieving the presence of all students in local schools, including those vulnerable to exclusionary pressures (Ainscow \& Miles, 2008). Some have taken the definition further to cover the placement of students with SEN in regular or ordinary classes (Peters, 2003), while others take inclusion to be about participation not only in the curricula, but the communities and cultures of local schools (Booth \& Ainscow, 2011). It is clear from the kind of data used in this study and the results above that we have examined the presence of students and the process of SEN identification, and therefore have not explored the fuller concepts of inclusion, as a first step.

Future extensions of this study could include a follow-up analysis of more recent developments in academisation, such as the development of academies into trusts through the multi-academy trust system. New analysis could also focus on academisation effects in terms of the different areas of SEN.

\section{Data availability statement}

The data that support the findings of this study (the National Pupil Database) are available from the Department for Education. Restrictions apply to the availability of these data, which were used under licence for this study. Data are available from the Department for Education under certain conditions; the application process is described at www.gov.uk/government/collections/national-pupil-database. 


\section{Conflict of interest}

The authors do not have any conflict of interest to disclose.

\section{Ethics}

In this study we used secondary data analysis and did not collect any new data. The project has been approved by the ethics committee of [the University of Exeter].

\section{References}

Abdulkadiroğlu, A., Angrist, J. D., Dynarski, S. M., Kane, T. J. \& Pathak, P. A. (2011) Accountability and flexibility in public schools: Evidence from Boston's charters and pilots, The Quarterly fournal of Economics, 126(2), 699-748.

Abdulkadiroğlu, A., Angrist, J. D., Hull, P. D. \& Pathak, P. A. (2016) Charters without lotteries: Testing takeovers in New Orleans and Boston, American Economic Review, 106(7), 1878-1920.

Ainscow, M. \& Miles, S. (2008) Making education for all inclusive: Where next?, Prospects, 38(1), $15-34$.

Angrist, J. D., Dynarski, S. M., Kane, T. J., Pathak, P. A. \& Walters, C. R. (2012) Who benefits from KIPP?, Fournal of Policy Analysis and Management, 31(4), 837-860.

Barnard-Brak, L., Schmidt, M. \& Almekdash, M. H. (2018) Enrollment of students with disabilities in charter schools: Contemporary national and state level findings, Education Policy Analysis Archives, 26, 43.

Berends, M. (2015) Sociology and school choice: What we know after two decades of charter schools, Annual Review of Sociology, 41, 159-180.

Betts, J. R. \& Tang, Y. E. (2016) A meta-analysis of the literature on the effect of charter schools on student achievement. Available online at: https://eric.ed.gov/?xml:id=ED566972 (accessed 14 January 2020).

Black, A. (2019) Future secondary schools for diversity: Where are we now and were could we be?, Review of Education, 7(1), 36-87.

Booth, T. \& Ainscow, M. (2011) Index for inclusion: Developing learning and participation in schools (3rd edn) (Bristol, Centre for Studies on Inclusive Education).

Cirin, R. (2014) Do academies make use of their autonomy? Research report (London, Department for Education).

DfE (2011) Support and aspiration: A new approach to special educational needs and disability. A consultation (London, Department for Education).

DfE (2014) Special educational needs and disability code of practice: 0 to 25 years. Statutory guidance for organisations who work with and support children and young people with special educational needs and disabilities (London, Department of Education).

DfE (2018) Open academies and academy projects in development. Available online at: www.gov.uk/gov ernment/publications/open-academies-and-academy-projects-in-development (accessed 14 January 2020).

Dobbie, W. \& Fryer, R. G. (2013) Getting beneath the veil of effective schools: Evidence from New York City, American Economic Fournal: Applied Economics, 5(4), 28-60.

Eyles, A. \& Machin, S. J. (2015) The introduction of academy schools to England's education. CEPR Discussion Paper No. DP10772.

Eyles, A., Hupkau, C. \& Machin, S. (2016) Academies, charter and free schools: Do new school types deliver better outcomes?, Economic Policy, 31(87), 453-501.

Eyles, A., Machin, S. \& McNally, S. (2017) Unexpected school reform: Academisation of primary schools in England, fournal of Public Economics, 155(Suppl. C), 108-121.

Eyles, A., Machin, S. \& Silva, O. (2018) Academies 2 - the new batch: The changing nature of academy schools in England, Fiscal Studies, 39(1), 121-158. 
Fryer, R. G. (2014) Injecting charter school best practices into traditional public schools: Evidence from field experiments, The Quarterly fournal of Economics, 129(3), 1355-1407.

Galton, M. \& Mac Beath, J. (2015) Inclusion: Statements of intent. Report to the National Union of Teachers on the current state of special educational needs and disability provision (Cambridge, NUT/University of Cambridge).

Gleason, P., Clark, M., Tuttle, C. C. \& Dwoyer, E. (2010) The evaluation of charter school impacts (Washington, D.C., US Department of Education).

Gorard, S. (2014) The link between academies in England, pupil outcomes and local patterns of socio-economic segregation between schools, Research Papers in Education, 29(3), 268-284.

Heilbronn, R. (2016) Freedoms and perils: Academy schools in England, fournal of Philosophy of Education, 50(3), 306-318.

Husbands, C., Gilbert, C., Francis, B. \& Wigdortz, B. (2013) Unleashing greatness? Getting the best from an academised system. Report of the Academies Commission (London, Pearson).

Imbens, G. W. \& Angrist, J. D. (1994) Identification and estimation of local average treatment effects, Econometrica, 62(2), 467-475.

IPPR (2014) Whole system reform: England's schools and the middle tier (London, Institute for Public Policy Research).

Machin, S. \& Vignoles, A. (2006) Education policy in the UK (London, ERIC).

New Schools Network (2015) Comparison of different types of school. A guide to schools in England (London, New Schools Network). Available online at: www.newschoolsnetwork.org/sites/defa ult/files/files/pdf/Differences\%20across\%20school\%20types.pdf (accessed 14 January 2020).

Norwich, B. (2014) Changing policy and legislation and its effects on inclusive and special education: A perspective from England, British Fournal of Special Education, 41(4), 403-425.

Norwich, B. \& Black, A. (2015) The placement of secondary school students with Statements of Special Educational Needs in the more diversified system of English secondary schooling, British Fournal of Special Education, 42(2), 128-151.

Peters, S. J. (2003) Inclusive education: Achieving education for all by including those with disabilities and special education needs (Washington, D.C., World Bank).

Setren, E. (2015) Special education and English language learner students in Boston charter schools: Impact and classification (Cambridge, MA, Massachusetts Institute of Technology).

Slee, R. (2008) Beyond special and regular schooling? An inclusive education reform agenda, International Studies in Sociology of Education, 18(2), 99-116.

Tuchman, S. \& Wolf, P. J. (2017) Special education identification in the Louisiana scholarship program. Louisiana Scholarship Program Evaluation Report No. 8.

West, A. (2014) Academies in England and independent schools (fristaende skolor) in Sweden: Policy, privatisation, access and segregation, Research Papers in Education, 29(3), 330-350.

Wilson, J. (2011) Are England's academies more inclusive or more 'exclusive'? The impact of institutional change on the pupil profile of schools (London, Centre for the Economics of Education).

Winters, M. A. (2015) The myth about the special education gap, Education Next, 15(4).

Winters, M. A., Carpenter, D. M. \& Clayton, G. (2017) Does attending a charter school reduce the likelihood of being placed into special education? Evidence from Denver, Colorado, Educational Evaluation and Policy Analysis, 39(3), 448-463.

Zimmer, R. W. \& Guarino, C. M. (2013) Is there empirical evidence that charter schools "push out" low-performing students?, Educational Evaluation and Policy Analysis, 35 (4), 461-480.

\section{Appendix A}

\section{The instrumental variable specification}

Formally, for each period $t$, schools that convert at $t$ are included as the treatment group, and schools that convert at $t+\tau, \tau \in\{1,2$,$\} as the control group. This$ research design aims to compare the outcomes of pupils whose enrolment decision is 
made prior to the academisation; this avoids post-academisation endogeneity in terms of confounding factors in exiting school by pupils and the reclassification effect on new students at admission.

We use a binary 'intention-to-treat' (ITT) variable to indicate pupils' assignment to the treatment group (Fryer, 2014; Eyles \& Machin, 2015; Eyles et al., 2017), where at the baseline period $t-1$, pupils that enrol in treatment schools are assigned with an intention-to-treat status ITT $_{i s t}=1$, and pupils that enrol in control schools are assigned $\mathrm{ITT}_{i s t}=0$. For subsequent periods after academisation $t+\tau, \tau \in\{0,1,2\}$, the reclassification outcome is specified as $R_{i s t}^{\tau}=1$ when the SEN status for pupil $i$ at baseline period $t-1$ has been reclassified as of $t+\tau$. For the 'within' reclassification outcomes, aside from the standard fixed-effects model in Equation (1), we specify the instrumental variable design as:

(2) $A_{i s t}=\theta_{1} \mathrm{ITT}_{i s t}+\boldsymbol{X}_{i s t}^{\prime} \beta+\alpha_{s}+\alpha_{t}+\epsilon_{i s t}$,

(3) $R_{i s t}^{\tau}=\theta_{2} \mathrm{ITT}_{i s t}+\boldsymbol{X}_{i s t}^{\prime} \beta+\alpha_{s}+\alpha_{t}+\epsilon_{i s t}$,

As discussed earlier, $A_{i s t}$ denotes the academisation status of school $s$ that pupil $i$ attends at time $t$, and $\delta^{\prime}=\frac{\theta_{1}}{\theta_{2}}=E\left(R_{i s t, A=1}^{\tau}-R_{i s t, A=0}^{\tau} \mid A_{\mathrm{ITT}=1}>A_{\mathrm{ITT}=0}\right)$ measures the effect of academisation on the probability of reclassification for legacy-enrolled pupils that 'comply' with the treatment assignment. This removes the influence of the category of pupils who move to other schools and are reclassified at admission.

(4) $S_{i s t}^{\tau}=\delta \mathrm{ITT}_{i s t}+\boldsymbol{X}^{\prime}{ }_{i s t} \beta+\alpha_{s}+\alpha_{t}+\epsilon_{i s t}$,

For the academisation effect on switching schools $S_{i s t}^{\tau}$, pupils' treatment group assignment ITT $_{i s t}$ is used as the treatment variable, and therefore the fixed-effects models are specified.

For the 'within' models, in addition to the pupil-level control variables discussed in the intake models, we also control for pupils' grades (year). 